\title{
Numerical Modeling of the Seismic Out-of-Plane Response of a Plain and TRM-Strengthened Rammed Earth Subassembly
}

\author{
Reza Allahvirdizadeh*; Daniel V. Oliveira; Rui A. Silva \\ ISISE, University of Minho, Department of Civil Engineering, Azurém, P-4800-058, Guimarães, Portugal
}

(1)

Abstract: The importance of raw earth is highlighted by the millions of persons living in earthen buildings around the World and by numerous historical monuments made of this material. Its widely availability led to the development of a variety of building techniques, including rammed earth, which is the main focus of this study. Similarly to unreinforced masonry structures, rammed earth buildings acceptably withstand gravity loads, but are significantly vulnerable to earthquakes. In this regard, great attention has been put on the proposal of efficient, compatible, affordable and reversible strengthening solutions. However, very limited studies address either the experimental testing or modeling of the seismic response of such buildings. The current study investigates the seismic out-of-plane performance of a plain and subsequently strengthened rammed earth subassembly (U-shape) using an advanced finite element modeling approach calibrated based on previously conducted small-scale experiments. Here, failure mechanisms, corresponding capacity and efficiency of the adopted strengthening solution (low-cost textile-reinforced mortar) are evaluated by means of pushover analyses. Then, the reliability of the pushover analyses is assessed by comparing its outcomes with that of the incremental dynamic analyses. In general, the failure was found to be governed by overturning of the web wall due to its detachment from the wing walls, while the strengthening was found to increase the capacity and delay the damage development.

Keywords: Rammed earth; Nonlinear FE modeling; Out-of-plane behavior; TRM strengthening; Pushover; Dynamic analysis.

\section{Introduction}

Earth, as the most worldwide available material, was one of the first building materials used for manmade constructions. In this regard, many traditional building techniques have been developed, among which the most known are adobe masonry and rammed earth. As a consequence, many historical monuments made of raw earth

\footnotetext{
*Corresponding author, email: allahvirdizadeh@gmail.com
} 
can be found spread worldwide. Furthermore, the low associated building costs led this material to be an appropriate choice for low income societies, as well as for hardly accessible regions and isolated rural areas; which caused that approximately $30-40 \%$ of the world population to live or work in earthen constructions [1], although this figure may be somehow exaggerated nowadays. Furthermore, the green nature of raw earth leads it to be considered as a possible choice for future sustainable constructions. Hence, it became necessary to understand the behavior of earthen buildings, not only for modern design objectives, but also for the repair and strengthening of existing built heritage. To achieve this goal, it is essential to recognize their weaknesses under different loading conditions and circumstances. In this regard, it was previously observed that several factors such as rainwater, soluble salts, and temperature oscillations can lead to damage occurrence [2]. From a structural point of view, earthen constructions show an acceptable behavior under gravity loads, but they are strongly endangered with respect to lateral loads, like other types of unreinforced masonry structures. Furthermore, many earthen constructions are located in regions with medium or high seismic hazard. In this regard, many people inhabiting earth constructions have been severely affected in recent earthquakes, as for instance in Erzinkan at Turkey (1992), Bam at Iran (2003), Pisco at Peru (2007) and Concepción at Chile (2010).

The current study is focused on rammed earth construction. This technique is well-known in all continents (chineh in Iran, taipa in Portugal, tapial in Spain, pisé in France, terra battuta in Italy, stampflehm in Germany, hangtu in China, and pakhsa in Uzbekistan). Earth with an adequate moisture content is placed between two parallel panels (formworks which are interconnected by spacers) and is compacted (either manually or using pneumatic rammers). Its main ingredients are gravel, sand, silt, clay, water, and in some cases, additives. With respect to additives, rammed earth is categorized into two general classes; i.e. unstabilized rammed earth (i.e. without any artificial additives) and stabilized rammed earth, which contains binders such as cement or lime. Typically, the panels dislocate as layers (with an approximate thickness of $15 \mathrm{~cm}$ ) are built by initially running them horizontally along the perimeter of the construction and then moving vertically along the height to the next level [3].

Generally, rammed earth shows a weak response under compression forces and exhibits a very low tensile strength. Previous studies have reported tensile strength values for rammed earth constructions in a range of 0.10 to $0.15 \mathrm{MPa}$, which is very low in comparison with other conventional materials [4-5]. Several experimental studies (mostly uniaxial or diagonal compression tests on wallets) have been conducted to characterize its properties. However, the definition of its mechanical behavior is still a fundamental challenging 
task [2-9], as it depends on several parameters, such as particle size distribution, moisture content, compaction (rate and type), void ratio, cohesive strength of the particles, fiber content and quantity and type of additives. In other words, the mechanical performance of rammed earth is significantly influenced by hygrothermal conditions. Thus, a large scatter is observed among values reported in the literature, as exemplified in Table 1. As it is evident, the values reported for Young's modulus and shear modulus significantly vary in comparison to other parameters. Moreover, it was noticed that in spite of the layered construction procedure, the mechanical properties (especially the compressive strength and Young's modulus) do not meaningfully vary with respect to the direction of layers, namely perpendicular or parallel ones [8].

Table 1. Reported mechanical characteristics of rammed earth in different studies

\begin{tabular}{cccccccc}
\hline \hline Reference & $\begin{array}{c}\boldsymbol{\rho} \\
\left(\mathbf{k g} / \mathbf{m}^{3}\right)\end{array}$ & $\begin{array}{c}\boldsymbol{E} \\
\left(\mathbf{N} / \mathbf{m m}^{2}\right)\end{array}$ & $\begin{array}{c}\boldsymbol{f}_{c} \\
(\mathbf{M P a})\end{array}$ & $\begin{array}{c}\boldsymbol{f}_{\boldsymbol{t}} \\
(\mathbf{M P a})\end{array}$ & $\begin{array}{c}\boldsymbol{f}_{\boldsymbol{v}} \\
(\mathbf{M P a})\end{array}$ & $\begin{array}{c}\boldsymbol{G} \\
\left(\mathbf{N} / \mathbf{m m}^{2}\right)\end{array}$ & $\begin{array}{c}\boldsymbol{v} \\
(-)\end{array}$ \\
\hline \hline $\begin{array}{c}\text { Lilley and Robinson } \\
\text { (1995) [7] }\end{array}$ & $1870-2170$ & - & $1.8-2.0$ & - & - & - & - \\
$\quad \begin{array}{l}\text { Yamin et al. } \\
\text { (2004) [5] }\end{array}$ & 1920 & 784.8 & 3.24 & 0.15 & 0.36 & - & - \\
$\quad \begin{array}{c}\text { Bui and Morel } \\
\text { (2009) [2] }\end{array}$ & 1800.0 & $90-105$ & 1.0 & - & - & - & - \\
$\begin{array}{c}\text { Maniatidis } \text { et al. } \\
\text { (2007) [8] }\end{array}$ & 1850.0 & 205 & 3.88 & - & - & - & - \\
$\quad \begin{array}{c}\text { Miccoli et al. } \\
\text { (2014) [9] }\end{array}$ & - & 4143 & 3.73 & - & 0.71 & 2326 & 0.27 \\
\hline \hline
\end{tabular}

Where $\rho$ is bulk density, $E$ is Young's modulus, $f_{c}$ is compressive strength, $f_{t}$ is tensile strength, $f_{v}$ is shear strength, $G$ is shear modulus and $v$ is Poisson's ratio.

As mentioned above, rammed earth buildings are very vulnerable to earthquake excitations. Widely observed failure modes in previous earthquakes include brittle failures such as falling over due to out-of-plane actions, cracks at edges and also at loading points where the load of the roof is transferred to the wall, losing connectivity due to weak connections and propagation of cracks due to close distance between openings and corners [10-11]. Several intervention solutions are proposed in the literature to mitigate vulnerability conditions of earthen structures; namely the repair of cracks with injection of compatible grouts (from physical, mechanical and chemical points of view) [12-13], strengthening with boundary wooden elements [5], strengthening with ring beams [14], and strengthening with textile reinforced mortars (TRM) [12].

TRM is also known as FRCM (Fiber Reinforced Cementitious Matrix) in the literature and its use has been lately gaining increasing attention for the strengthening of masonry structures [15]. This interest resulted from disadvantages observed in the strengthening of masonry resorting to FRP-based materials, namely inadequate compatibility with the substrate, poor fire/high-temperature resistance [16-17], low reversibility, brittle failure 
and lack of vapor permeability, which are seen as serious drawbacks with respect to their application on historical constructions [18].

Experimental studies have been recently conducted to characterize not only the material properties of TRM systems, but also to evaluate the improved response of strengthened structural components. Uniaxial tensile tests and single/double lap shear tests have been performed to obtain their stress-strain and textile, matrix and substrate interaction behaviors, respectively [15]. Regarding the stress-strain curves, three stages are typically distinguished, i.e. un-cracked, crack development and cracked. During the first stage, the behavior is linear, while the crack initiation onsets the second stage, where the stiffness is reduced. In the third stage, the cracks are stabilized and the load-bearing capacity increases up to failure. In the first two stages, the mechanical characteristics of the mortar, textile, and their interface contribute for the behavior, while the behavior in the last stage is controlled by the textile, despite the mortar matrix is still able to provide transversal load redistribution [19-20]. Moreover, it is worthwhile to note that different failure modes such as shear failure of substrate, interface failure between substrate and textile (so-called debonding) or interface failure between mortar and reinforcement, slippage of reinforcement within the mortar and failure of reinforcement have been observed depending on bond characteristics of the strengthening/substrate or mortar/textile [20-21].

In addition to the aforementioned small-scale tests, several experimental studies were conducted to assess the efficiency of TRM solutions on the in-plane and out-of-plane response of masonry walls [20,22]. Though, they were mainly applied to masonry, meaning that the efficiency of TRM strengthening on earthen constructions is basically unknown, mainly rammed earth one. Despite that, it is expected that the application of this solution may result in effective increase of the loading capacity or/and ductility. Additionally, the strengthening is expected to promote a further redistribution of stresses that may prevent (or delay) the integrity loss of structural components $[20,22]$.

In addition to experimental investigations, numerical modeling is also a powerful tool to better understand the behavior of earthen constructions. Generally, three different types of modeling approaches have been employed to investigate the response of rammed earth walls, i.e. simplified modeling (using limit analysis) [23], finite element modeling (FEM) and discrete element modeling (DEM). Due to the predominant nonlinear behavior of rammed earth, predicting its response by means of analytical or linear methods would be a cumbersome task, meaning that more advanced approaches should be adopted instead. In FEM modeling, two approaches are typically used, namely macro- and micro-modeling. The macro-modeling approach does not consider layered 
111 and anisotropic natures of rammed earth, as the material is assumed to be continuous and isotropic. In micromodeling, the rammed earth layers are discretized and the interaction occurring between layers is taken into account. Due to the greater detailing of micro-modeling, most of the available studies have employed the macromodeling approach. The major reasons supporting the decision of ignoring the micro-modeling approach are the lack of reliable data to define the behavior of the interfaces, the higher computational efforts and the fact that macro-modeling results in a global comparable accuracy with respect to micro-modeling [24]. In turn, DEM is less popular than FEM, but some researchers employed it to take into account the influence of layers in the response. Though, it was concluded that the results obtained by models with or without interfaces are similar, even when very low values of interface parameters are considered [25].

It is worthwhile to note that previous studies obtained relatively accurate outcomes under in-plane loading in comparison to the experimental results. On the other hand, predicting the out-of-plane response may lead to significantly diverse outcomes and still is a challenging task [26].

The current study investigates the out-of-plane seismic response of a rammed earth component and assesses the strengthening efficiency of a selected TRM solution. In this regard, the FEM is adopted to simulate the structural behavior in both cases. The numerical models were defined with basis on experimental results available in the literature and were subjected to mass proportional pushover analyses to assess their loading capacity and corresponding failure modes. Additionally, incremental dynamic analyses were performed to evaluate the reliability of pushover analyses for rammed earth structural components.

This study was carried out within the framework of an ongoing research project on the seismic behavior of rammed earth, where experimental models, similar to those simulated here numerically, will be tested on the shaking table. Given the novelty of the shaking table testing of plain and strengthened rammed earth components, this numerical work has the twofold purpose of gaining insight into the out-of-plane seismic behavior of plain and TRM-strengthened rammed earth and guiding the design of the experimental campaign.

\section{Rammed Earth Structural Subassembly} small components (wallets). It is evident that in spite of providing valuable information at the material level, they do not provide a general understanding of possible building failure mechanisms. Furthermore, the referred 
as connections or perpendicular walls were neglected. In this regard, testing structural components on shaking table is a more appropriate approach to clarify probable damage under earthquake excitations and also to assess the applicability of strengthening solutions in improving the seismic behavior. Due to the costly and timeconsuming process of testing components on shaking table, an efficient and accurate experimental test design requires the analysis of possible structural responses by means of advanced numerical analyses.

The geometry of the subassembly should be representative of real constructions as much as possible, satisfying also geometry and weight limitations of the shaking table, and must be designed in such a way as to fail according to the expected behavior (i.e. out-of-plane as aimed in the current study).

Alentejo region in southern Portugal has an extensive number of monuments and buildings built in rammed earth. Some of these typical vernacular buildings in this region are shown in Fig. 1. Thus, a survey of eleven representative rammed earth buildings located in this region was taken into account to define the geometry of the model. They were all single story buildings constructed before the 1950s. It was observed that in all cases the thickness of walls is of about $0.5 \mathrm{~m}$ [27]; hence the same dimension is adopted in the current study. The height, length and longitudinal to transversal length ratio found in the sample are around $2.2 \pm 0.3 \mathrm{~m}, 3.7 \pm 1.5 \mathrm{~m}$ and $2.2 \pm 1.0$, respectively.
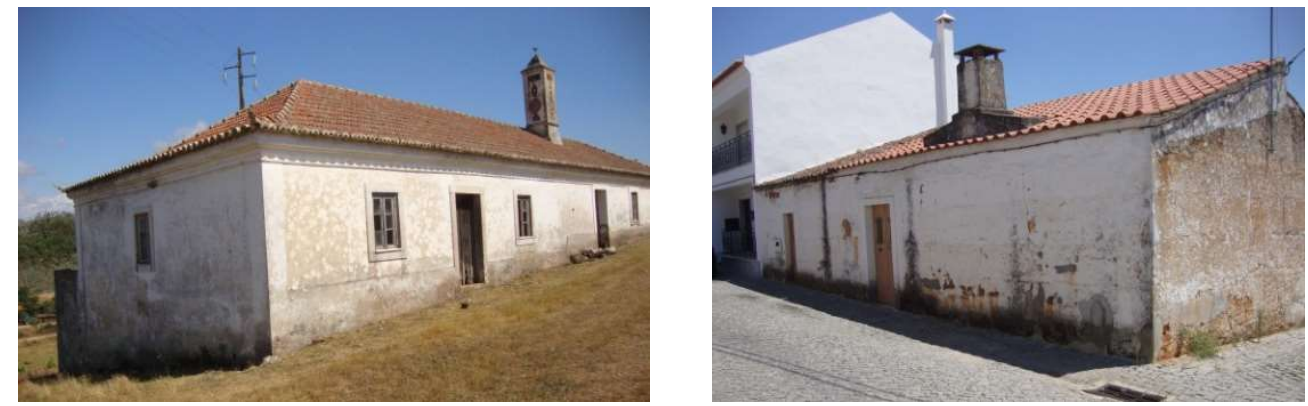

Fig. 1. Typical vernacular rammed earth buildings in southern Portugal

Regarding the roof typology of rammed earth buildings, they were constructed by lightweight timber shed or gable roofs, which normally support on the walls. Nevertheless, the roof system does not impose a significant load to the walls in this constructional system. Also, the low in-plane stiffness of roofs does not allow these structures to be considered as box-behavior.

On the other hand, some samples of typical plan view of the surveyed vernacular rammed earth buildings are shown in Fig. 2. As it can be seen, the walls are generally supported by perpendicular walls (which are highlighted in red). Thus, it seems that a U-shape component could be a representative geometry for typical rammed earth walls. 

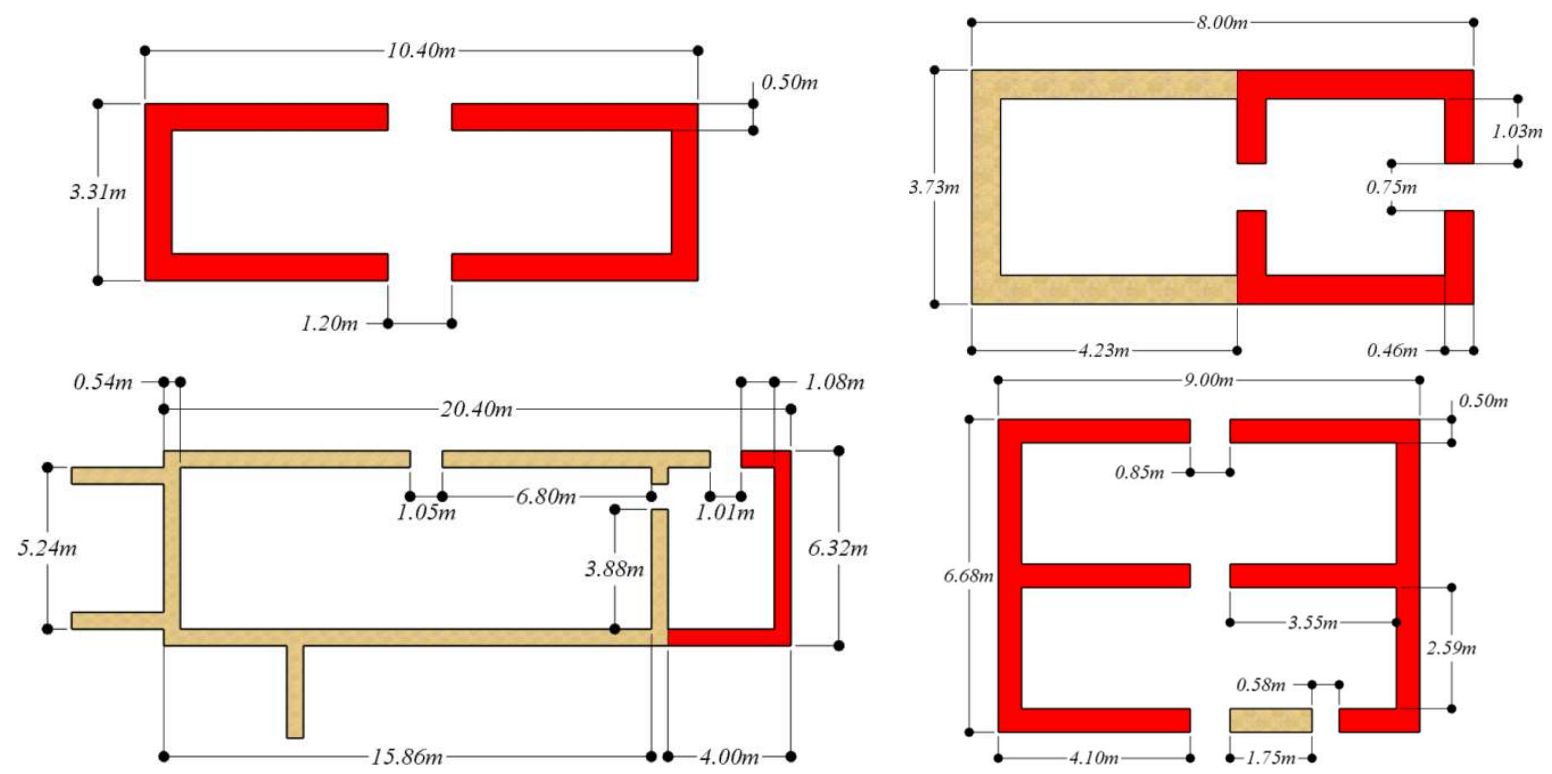

Fig. 2. Plan samples of surveyed typical vernacular rammed earth buildings in Alentejo region, southern Portugal [27]

In addition to the desirable representative conditions, the outcomes of the current study are aimed to be used in designing a full-scale shaking table test in near future. Therefore, it was essential to consider a model with geometry within practical dimension ranges (obtained from the surveyed buildings), which is supported by transversal walls and satisfies maximum size and weight limitations of the shaking table. The shaking table to test the rammed earth model is the one from the Portuguese national civil engineering laboratory (LNEC), where the maximum weight of models is limited to 21 tons. Taking into account both representativeness and technical conditions, the geometry of the U-shape subassembly presented in Fig. 3 has been fixed with a constant wall thickness of $0.5 \mathrm{~m}$. It is noted that the expected weight of the model is 18 tons (for a rammed earth density of about $2000 \mathrm{~kg} / \mathrm{m}^{3}$ [28]).

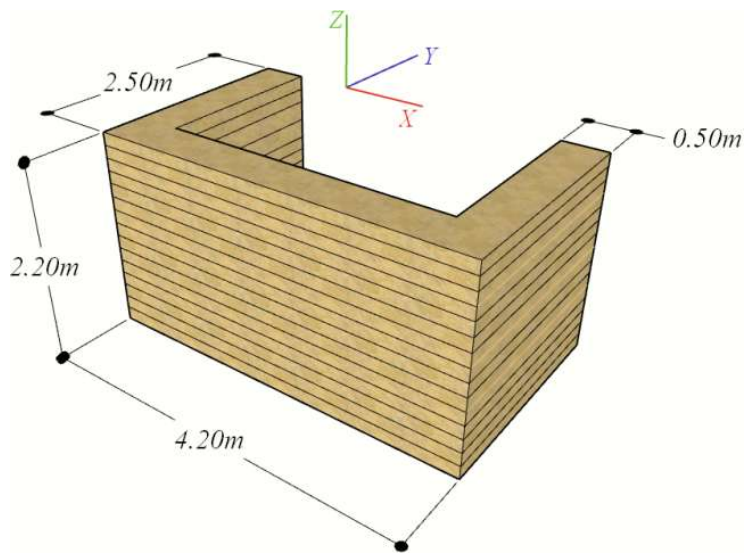

Fig.3. Geometry of the out-of-plane model 


\section{Mechanical Characteristics and Modeling}

FEM models were prepared and computed using the software DIANA 10.2 [29]. To perform the nonlinear finite element modeling of rammed earth subassembly, the definition of proper material properties for rammed earth, strengthening (including textile and mortar) and their interfaces (between substrate/strengthening and mortar/mesh grid) was required. The following sections present the adopted constitutive laws and employed modeling approach.

\subsection{Rammed earth material}

The material behavior of the rammed earth was simulated by means of the total strain rotating crack model (TSRCM) implemented in DIANA 10.2 [29]. Furthermore, the marked nonlinear behavior of rammed earth in compression, highlighted in the literature, led authors to adopt a multi-linear relationship, as recommended in $[14,24]$. The adopted relationship is depicted in Fig. 4a and was defined by averaging the experimental stressstrain curves obtained from compression tests on cylindrical rammed earth specimens reported in [30]. It is worthwhile to note that due to lack of reliable experimental data regarding the post-peak branch, the expected behavior (shown by dashed line) was estimated by continuing the curve with the same slope of the experimental data. The behavior in tension was assumed to follow an exponential relationship and the respective parameters are calibrated values from a previous numerical study [28] on the simulation of the shear behavior of rammed earth wallets tested under diagonal compression (see also [30]). The adopted relationship in tension and respective parameters are depicted in Fig. 4b.

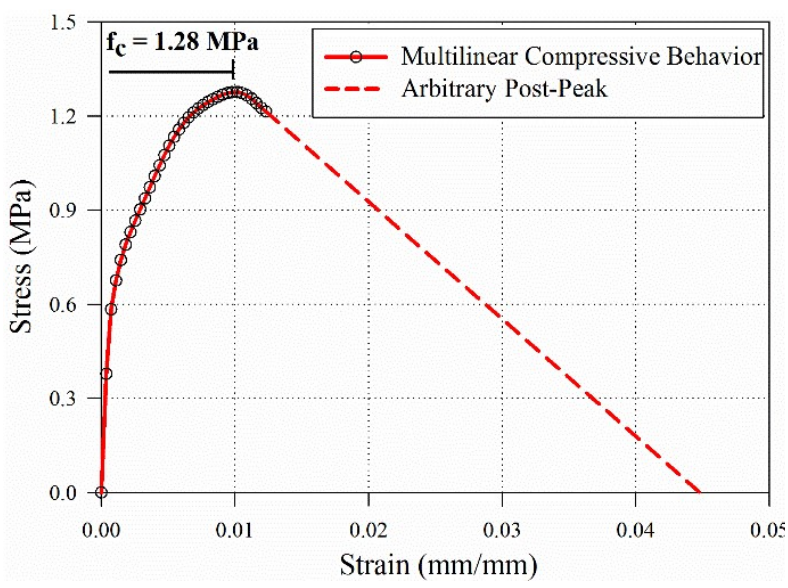

(a)

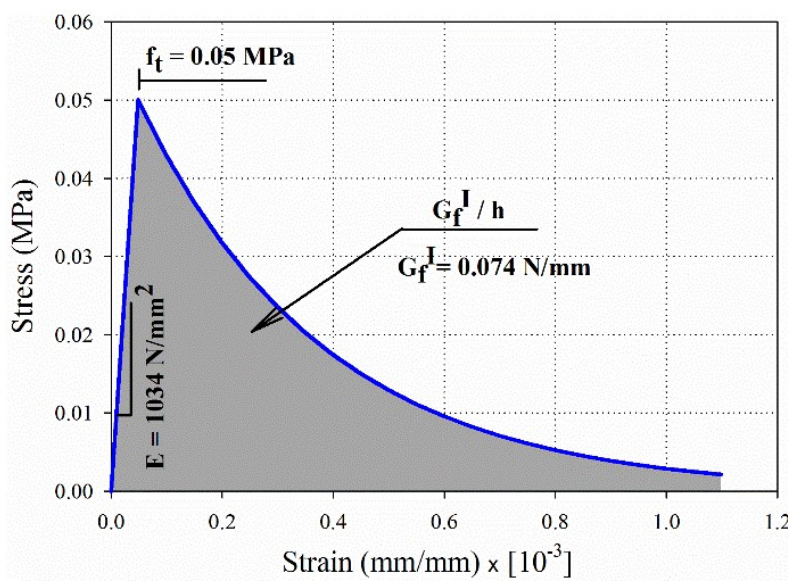

(b)

Fig. 4. Adopted stress-strain relationships for rammed earth: (a) multi-linear relationship in compression (b) exponential relationship in tension ( $E$ is Young's modulus, $f_{t}$ is the tensile strength, $G_{f f}$ is the mode-I tensile fracture energy and $f_{c}$ is the compressive strength) 
198 In order to make the numerical outcomes independent from the size of the element, the crack bandwidth $(h)$ was assumed to be square root of the element area $(A)$. Note that the aforementioned experimental data resulted from

200 specimens manufactured with soil collected from the same region where the geometrical survey was conducted 201 (Alentejo region, southern Portugal).

\subsection{TRM composite material}

The selection of the TRM strengthening solution to be applied to the plain rammed earth model resulted from a recent research work proposing and characterizing different low-cost textile reinforced mortars (LC-TRM) solutions [31-32]. It should be noted that the fundamental concept of the proposed strengthening solution consists in using compatible (from the physical, chemical and mechanical points of view), affordable and readily available materials in order to generalize its use. The aforementioned studies evaluated several low-cost reinforcing meshes available locally, among which a glass fiber mesh (denoted hereafter as G1) and a nylon fiber mesh (denoted hereafter as G2) were selected to integrate the strengthening solution. With respect to the other meshes evaluated, G1 presents higher strength, low deformation capacity and linear behavior up to peak load followed by a fragile post-peak; whereas G2 has much less stiffness and strength, with a clear hardening region, again ending at a brittle failure [32]. The proposed LC-TRM solution consists additionally of an earth based mortar prepared with the same soil used in the construction of the rammed earth specimens tested in [30].

Regarding the modeling of the material behavior of the LC-TRM strengthening, a similar approach to that of rammed earth was assumed, namely using the TSRCM. This material model requires knowing the stress-strain behavior of the composite material in tension and compression. The behavior in tension was assumed with basis on the composite tensile behavior (considering both mortar and mesh together) obtained from direct tensile tests [31], as depicted in Fig.5 (shown as solid lines). The aforementioned tests were conducted on coupon specimens with dimensions of $100 \times 400 \mathrm{~mm}^{2}$, based on the procedure of ASTM D6637. The specimens were composed of two low cost meshes available locally and an earth-based mortar. The tests were conducted by applying a tensile load under monotonic displacement control and by measuring the axial deformations [31]. It should be noted that within this modeling approach a perfect bond hypothesis between the mesh and mortar is assumed. The numerical behavior in tension consisted of a typical tri-linear relationship obtained by averaging of the experimental data (see dashed lines in Fig.5). 


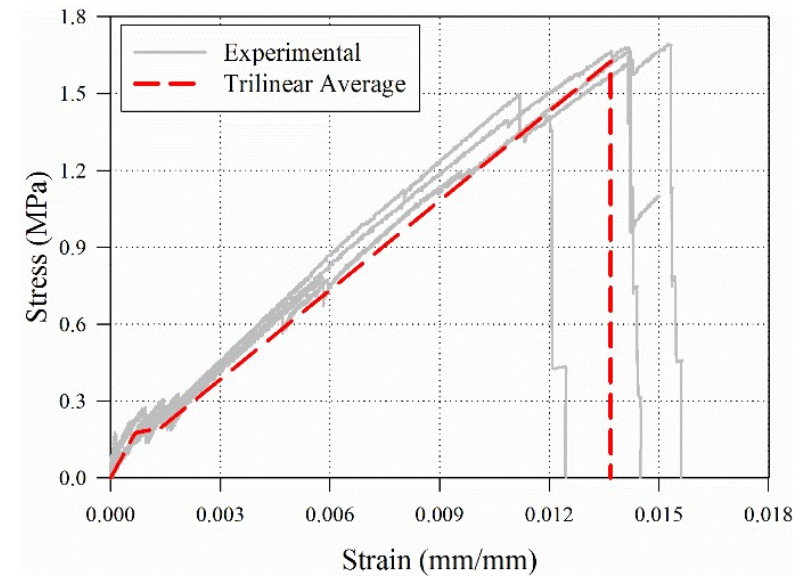

(a)

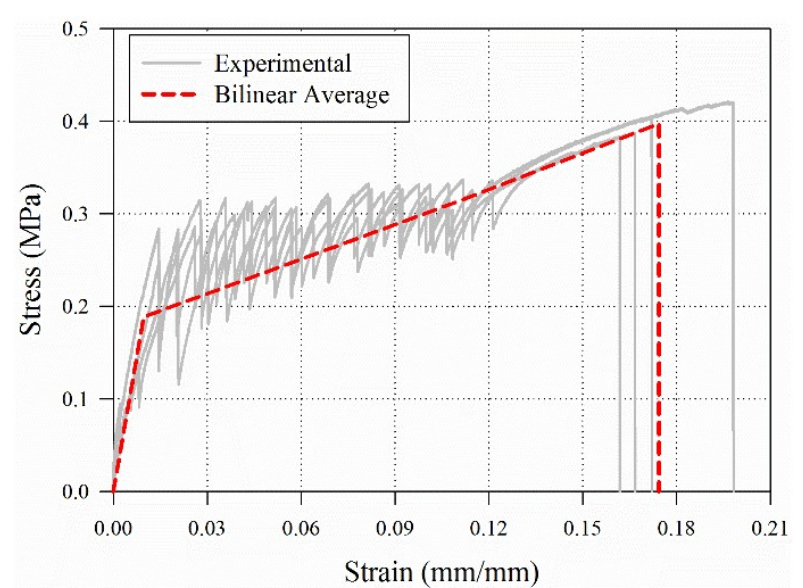

(b)

\begin{tabular}{|c|c|c|c|c|c|c|c|c|}
\hline Material & $\begin{array}{c}E \\
\left(\mathrm{~N} / \mathbf{m m}^{2}\right)\end{array}$ & $\begin{array}{c}v \\
(-)\end{array}$ & $\begin{array}{c}\rho \\
\left(\mathrm{kg} / \mathrm{m}^{3}\right)\end{array}$ & $\begin{array}{c}f_{c} \\
(\mathbf{M P a})\end{array}$ & $\begin{array}{c}f_{t} \\
(\mathbf{M P a})\end{array}$ & $\begin{array}{c}G_{f}^{I_{f}} \\
(\mathbf{N} / \mathbf{m m})\end{array}$ & $\begin{array}{l}\varepsilon u t \\
(-)\end{array}$ & Comment \\
\hline Rammed Earth & 1034 & 0.27 & 2000 & 1.28 & 0.05 & 0.074 & - & $\begin{array}{c}\text { Multilinear compressive } \\
\text { and exponential tensile } \\
\text { behavior }\end{array}$ \\
\hline LC-TRM (G1) & 3431 & 0.27 & 1810 & 1.30 & 1.62 & - & 0.0137 & $\begin{array}{l}\text { Multilinear compressive } \\
\text { and trilinear tensile } \\
\text { behavior }\end{array}$ \\
\hline LC-TRM (G2) & 3431 & 0.27 & 1810 & 1.30 & 0.40 & - & 0.1744 & $\begin{array}{l}\text { Multilinear compressive } \\
\text { and bilinear tensile } \\
\text { behavior }\end{array}$ \\
\hline
\end{tabular}

Fig.5. Tri-linear numerical curves based on the experimental uniaxial tensile stress-strain curves of TRM composite specimens: (a) G1 mesh (b) G2 mesh

The behavior of the LC-TRM in compression is mainly governed by the behavior of the mortar, meaning that the contribution of the mesh can be disregarded. Thus, the experimental stress-strain curves of mortar cylinders tested under uniaxial compression were used to define the numerical behavior in compression (see [31]). These curves present also an expressive nonlinear behavior, which led the multi-linear relationship to be assumed for this study by averaging experimental data (see Fig.6a). Here, an estimated post-peak descending branch was also proposed (shown as dashed line) to take into account the stress degradation of the TRM composite in compression. Finally, the complete composite stress-strain behaviors are presented in Fig.6b and c. Considering all, the adopted material properties in the current article are reported in Table 2.

Where $E$ is Young's modulus, $v$ is Poisson's ratio, $\rho$ is bulk density, $f_{c}$ is compressive strength, $f_{t}$ is tensile strength, $G_{f}^{I}$ is mode-I tensile fracture energy and $\varepsilon_{u t}$ is ultimate tensile strain. 


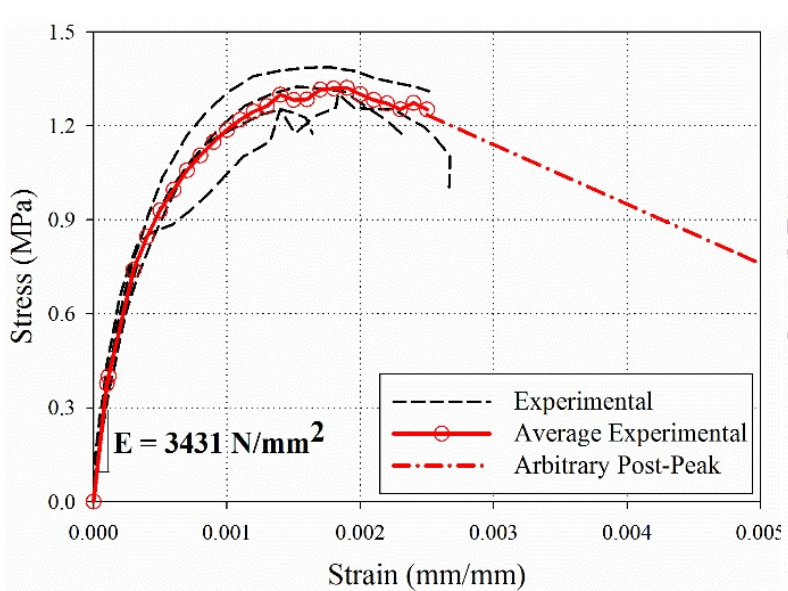

(a)

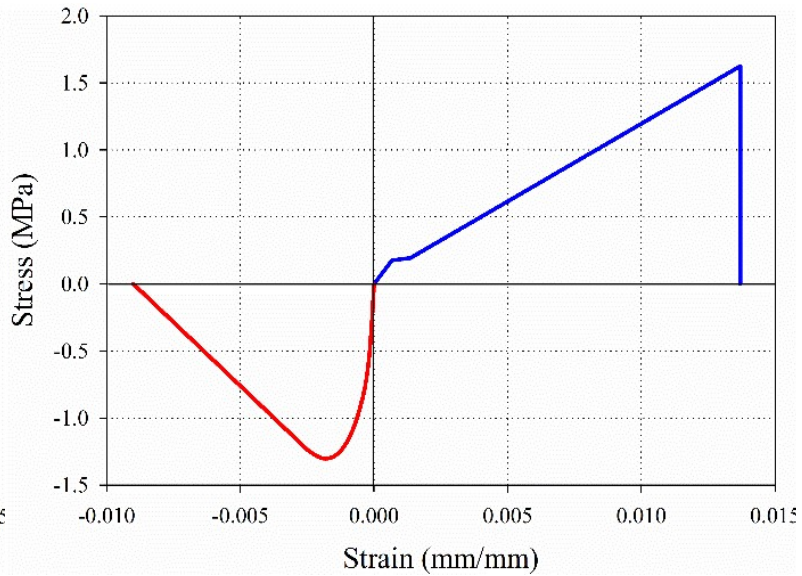

(b)

The FEM 3D modeling of structural walls typically follows two main approaches, namely by considering shell

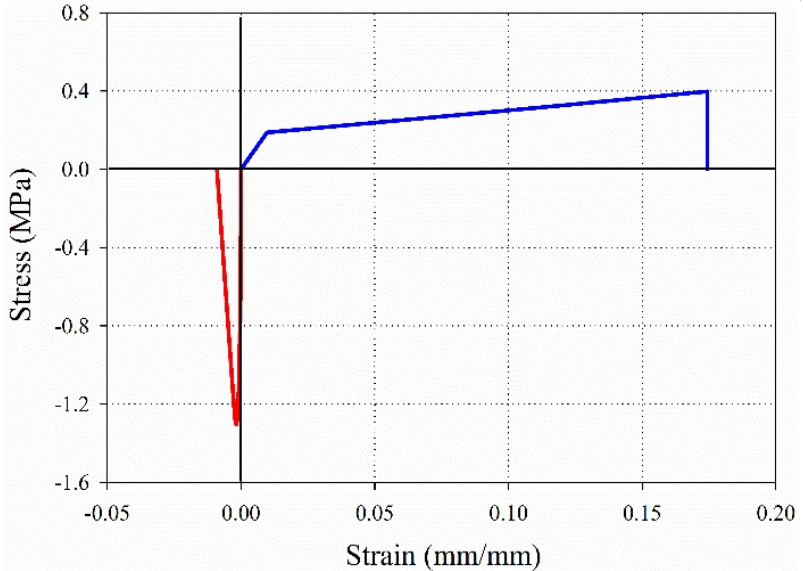

(c)

Fig.6. Stress-strain behavior of the LC-TRM strengthening: (a) behavior of mortar in compression; (b) full behavior with $\mathrm{G} 1$ mesh (c) full behavior with $\mathrm{G} 2$ mesh

\subsection{Numerical modeling approach} or solid elements, being the first less compute-intensive and the second more accurate in accounting for threedimensional effects. Here, both approaches were used in a first phase to compare their outcomes and concluded about their accuracy. The shell model was prepared by considering the mid-section planes of each wall (schematically depicted in Fig.7a). As a first consideration, this approach is shown to introduce modeling incoherencies. For instance, the length of the wing cantilevers is not properly modeled, as they present higher length than in the reality. Furthermore, the overlapping thicknesses of the walls lead to misleading considerations of the self-weight and mass distribution, and thus of the inertial forces. The implications of these issues in the modeling are discussed later.

The shell model was discretized by means of 8-node quadrilateral curved shell elements CQ40S (see Fig.7b), while 20-node iso-parametric brick elements CHX60 (Fig.7c) were used in the case of the solid model. Moreover, the integration scheme of the shell elements consisted of $2 \times 2$ with 7 integration layers, while the 


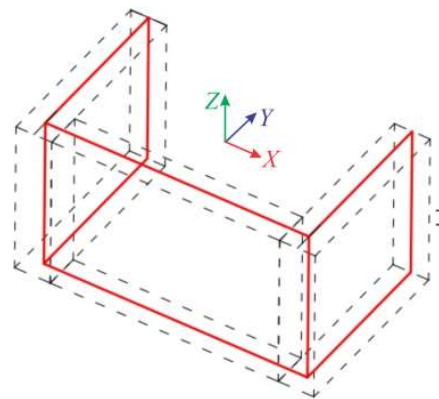

(a)

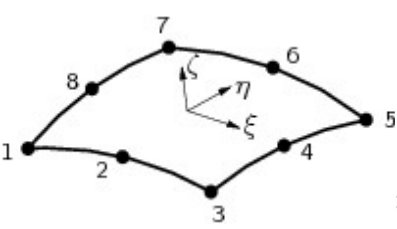

(b)

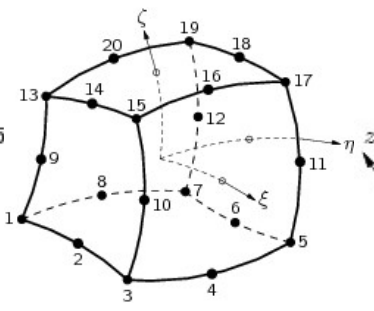

(c)

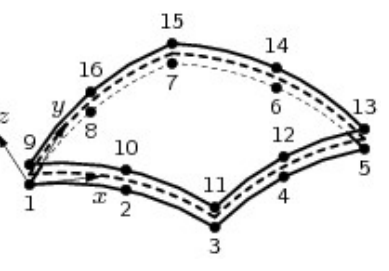

(d)

Fig.7. Definition of the out-of-plane model: (a) schematic view of the shell model (b) CQ40S shell element [29] (c) CHX60 brick element [29] (d) CQ48I interface element [29]

Mesh sensitivity analysis was conducted to verify the proper mesh size. Hence, three mesh sizes including $25 \mathrm{~mm}$ (benchmark), $50 \mathrm{~mm}$ and $100 \mathrm{~mm}$ were taken into account. Subsequently, the models were subjected to their self-weight and pushed by a lateral mass-proportional load equal to self-weight. Comparing both lateral displacements and base shear values with those of the benchmark model revealed that the model with mesh size equal to $100 \mathrm{~mm}$ leads to a maximum $1 \%$ error. Hence, this mesh size was adopted for further investigations. Additionally, the resulted vertical reactions were compared with calculated self-weight of the models to ensure the validity of the models. More details regarding the employed numerical modeling approach can be found in [33].

It is worthwhile to mention that the current approach has previously being used successfully to model behavior of plain rammed earth wallets. The obtained outcomes presented a good agreement from both capacity (load and displacement) prediction and damage aspects $[13,24,28]$. 


\section{Modal Analyses}

An eigenvalue analysis was conducted for all models (plain/strengthened and solid/shell) by considering the 20 first modes of vibration, which cover most of the modal mass participation in the dynamic behavior. Among them, those with the highest contributions for the plain models are reported in Table 3 . In general, mode shapes are very similar, but the shell discretization leads to a more flexible model (higher periods). This situation results from the definition of the geometry of the shell model by means of the mid-section of the component, which leads to an increased effective length of the walls (web and wings). Furthermore, the obtained effective modal mass of the shell model is different from that of the solid model.

Table 3. Dynamic properties of the plain model (solid and shell) obtained from modal analysis

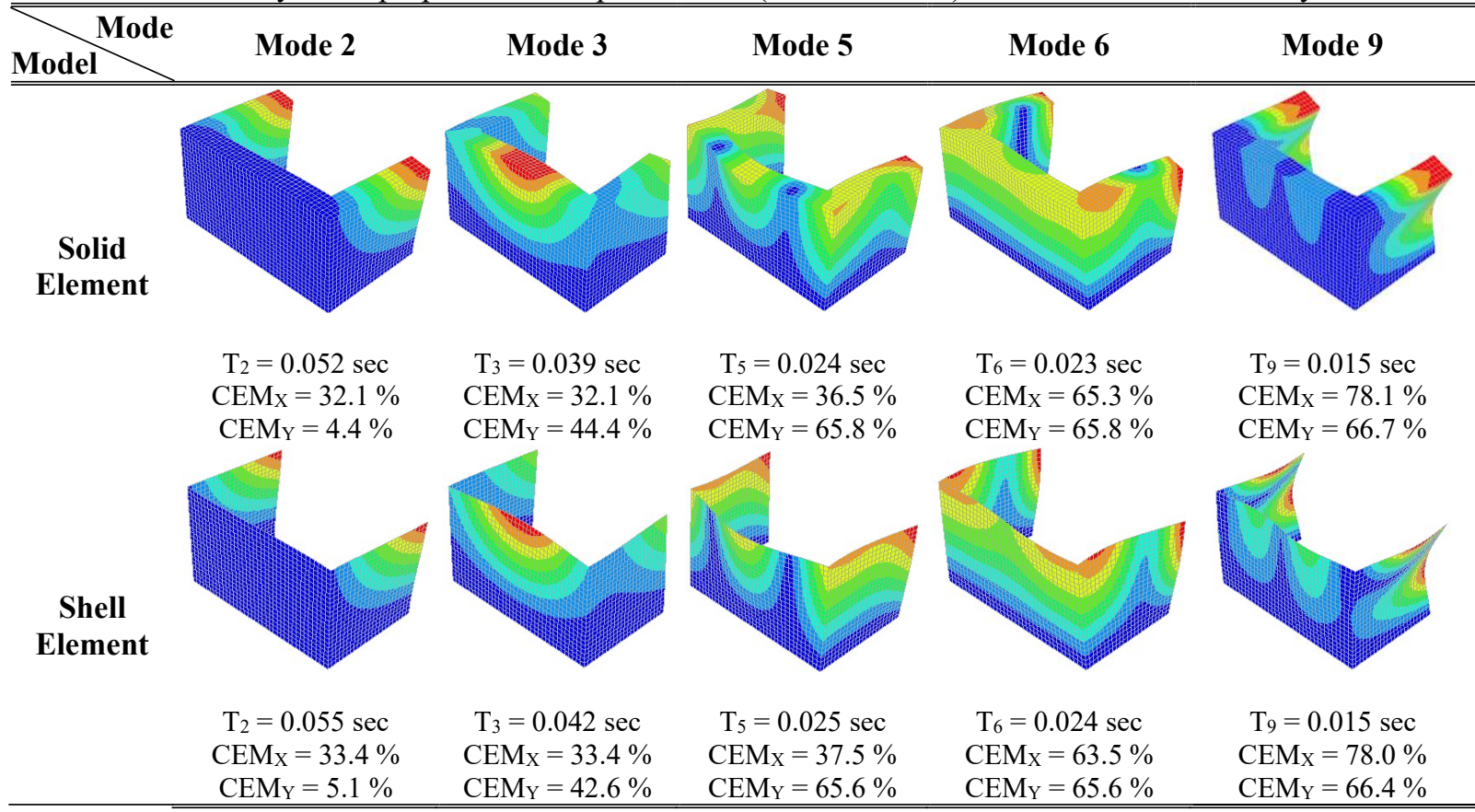

$T_{i}$ is the corresponding period of mode $i$ and CEM is the cumulative effective modal mass.

The same approach was followed for the strengthened model; though, only outcomes of the solid model are presented here for the sake of brevity. The implemented strengthening solution does not significantly increase the mass of the models, while a slight stiffness increment is observed, as the mode shapes, periods, and modal mass participation changed slightly (Table 4). The period values decreased in the strengthened model, while a slight increase in the cumulative effective modal mass was observed. This increment can be due to an improved integrity of the model provided by the adopted strengthening, meaning that some local modes may have been mitigated in the strengthened model. 


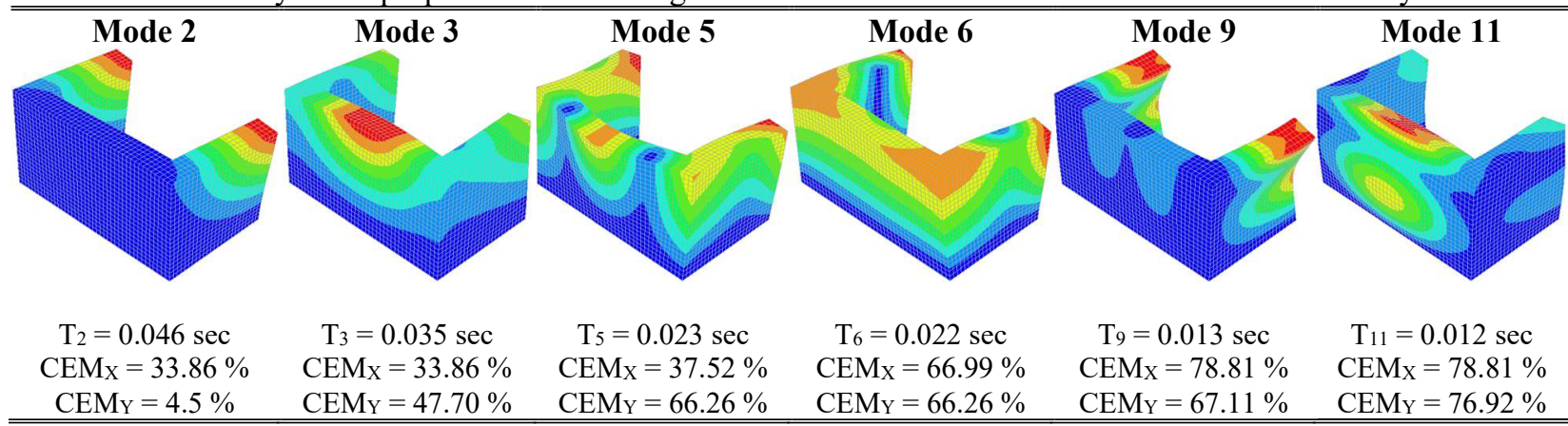

296

\section{Pushover Analyses}

As referred previously, the main objective of the current study is to investigate the seismic out-of-plane response of a representative rammed earth subassembly to be later tested on shaking table, aiming at predicting its possible failure modes and assessing the performance of the LC-TRM strengthening solution adopted. It is clear that performing nonlinear time-history analyses would result in more detailed information, but also at a high computational effort. On the other hand, nonlinear static analyses (so-called pushover) may lead to an acceptable simulation of the lateral response at lower computational effort, though the predicted damage pattern may differ significantly from the reality and the reliability of the estimated maximum lateral displacements can go beyond given acceptable limits [34-35]. In spite of such drawbacks, pushover analyses can provide a preliminary and general overview of the behavior, whereby they are widely used in the literature. Hence, this section presents the outcomes of the conducted pushover analyses. In this regard, a mass-proportional lateral load pattern was applied to push the shell and solid models. However, pushover analyses of the strengthened model were performed for the case of solid model only, to be justified later. The pushing was performed in the $y$-direction to induce the out-of-plane behavior of the web. It is worthwhile noting that due to the un-symmetric geometry of the models, analyses were performed for both positive (inside) and negative (outside) directions. Furthermore, the results are presented in two stages, i.e. at damage initiation stage (crack opening) and at the peak capacity.

\subsection{Plain model}

The pushover curves representing the seismic coefficient (normalized base shear at each step of analysis to the weight of the models) versus the lateral displacement of the control node (located at the top of the web's midsection) are presented in Fig.8. The pushing direction and considered control node are also shown in Fig.8. 
Pushing in the negative direction results in lower load and displacement capacities than those obtained for the models pushed in positive direction. This behavior is explained by the less effective supporting contribution of the wings in the former direction, which also explains the earlier damage initiation. For instance, in the case of the solid model, the damage onset in the negative direction occurs for a base shear ratio of approximately 0.2 , whereas in the case of the positive direction this value is of about 0.4 . Thus, it can be concluded that the negative direction is the direction limiting the response of the plain rammed earth model. As previously mentioned, the total strain rotating crack model is adopted in the current article to identify damage (crack) initiation and propagation, which follows a smeared cracking approach. Furthermore, the crack direction rotates according to the direction of the principal strains. Within this concept, the crack initiates when the principal tensile stress reaches the tensile strength of the material. Then, the tensile strength degradation follows the predefined softening rule [29].

With regard to the post-peak behavior, the models pushed in the negative direction experience a sudden drop immediately after the peak, while pushing it in the positive direction results in a smooth degradation of the capacity. In other words, the brittle response of the subassembly when pushed outside the wings results from the overturning of the web due to loss of connection with the wings. When the models are pushed towards the wings, the connections are compressed, meaning that the wings are able to counteract the overturning movement.

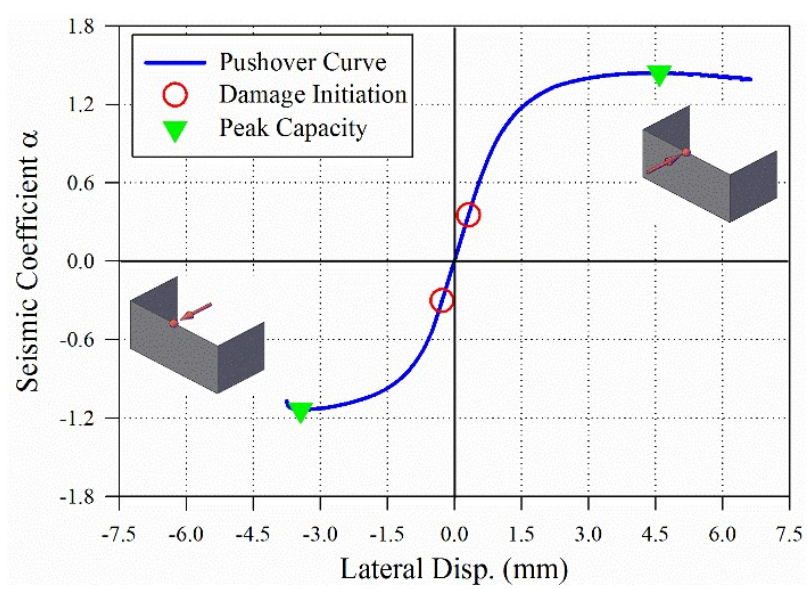

(a)

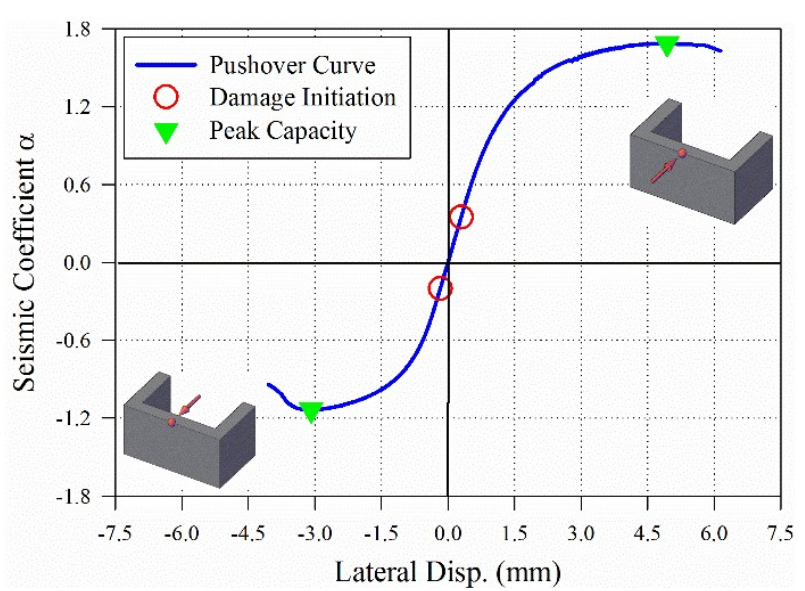

(b)

Fig.8. Pushover curves of the plain models: (a) shell model (b) solid model

The failure mechanisms of the models were investigated by means of the lateral displacement and principal tensile strain contours at the peak capacity of the models. The contour maps of the experienced lateral displacements at the peak capacity of the both solid and shell models pushed in positive and negative directions 


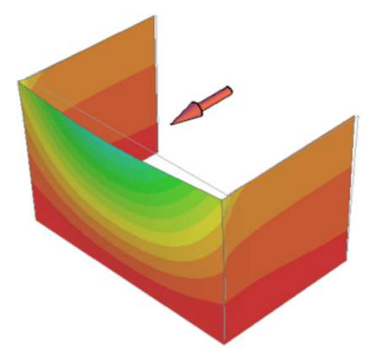

(a)

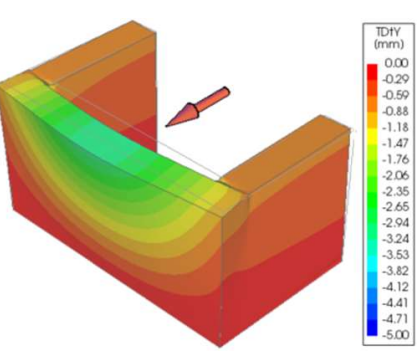

(b)

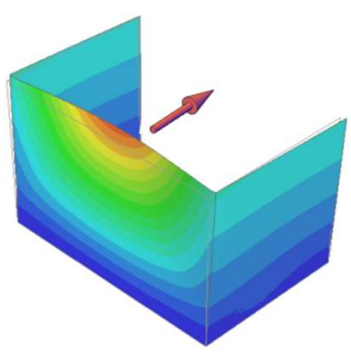

(c)

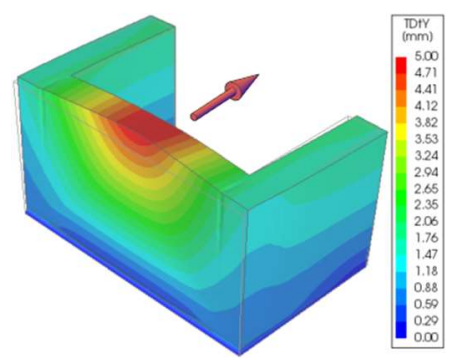

(d)

347 Fig.9. Total lateral displacements at the peak capacity: (a) shell model pushed in the negative direction (b) solid 348 model pushed in the negative direction (c) shell model pushed in the positive direction (d) solid model pushed in the positive direction

350 A more detailed insight on damage detection was achieved by investigating the principal tensile strains at the peak capacity of the models, as presented in Fig. 10. The highest values of the principal tensile strains

Considering the resulted capacities and damage states, the solid modeling approach seems to lead to more the solid model. 


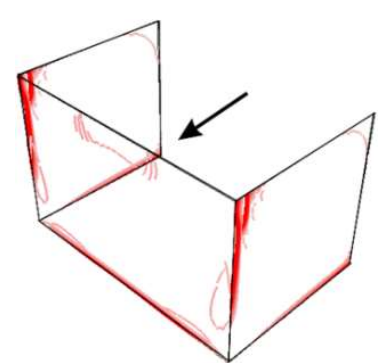

(a)

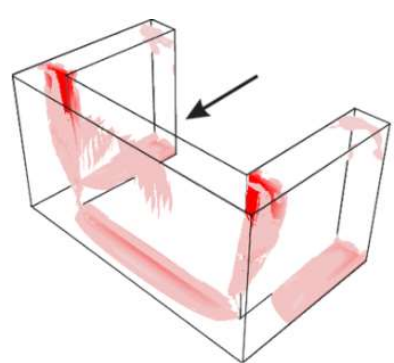

(b)

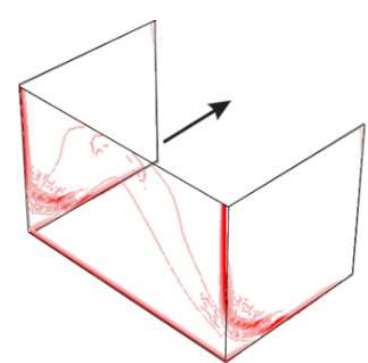

(c)

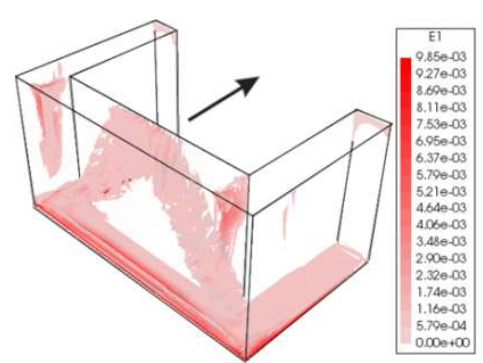

(d)

Fig. 10. Principal tensile strains at the peak capacity of the models: (a) shell model pushed in the negative direction (b) solid model pushed in the negative direction (c) shell model pushed in the positive direction (b) solid model pushed in the positive direction

\subsection{TRM-strengthened model}

This subsection aims at evaluating the influence of applying LC-TRM on the seismic out-of-plane performance of the rammed earth component. Following common practical applications, the strengthening is applied on both sides (inner and outer) of the whole model (both web and wing walls).

Considering that both G1 and G2 meshes have a relatively similar cost, around $0.8 \mathrm{Euro} / \mathrm{m}^{2}$ [31], the rational selection between these two meshes is related to the best structural performance. In this regard, both meshes are examined numerically by pushing the solid model in the negative out-of-plane direction (see Fig.7) to assess their strengthening effectiveness. The corresponding pushover curves are shown in Fig.11. As it can be seen, the strengthening with the G2 LC-TRM results in a $7.0 \%$ and $13 \%$ increase in displacement and load capacities, respectively; while for the G1 composite, the increases are about $45 \%$ and $29 \%$, for displacement and strength, respectively. In conclusion, using the G1 LC-TRM composite seems more reasonable, whereby the subsequent investigation is conducted using this particular solution.

Thus, the pushover curve of the strengthened model (with G1 mesh) in comparison with that of the plain one is presented in Fig.12. As it can be observed, the applied strengthening slightly increases the pre-peak stiffness of the model by controlling the cracking process, though it has no meaningful influence on the onset of damage, since it tends to initiate in the rammed earth. The most highlighted influence of the strengthening can be observed in the lateral displacement and load capacitates, which in the case of the negative direction leads to increase of $45 \%$ and $29 \%$, respectively. As previously discussed, the response in the positive direction is less critical than that in the negative one, but $131 \%$ and $31 \%$ improvement can be observed for displacement and load capacities, respectively. 


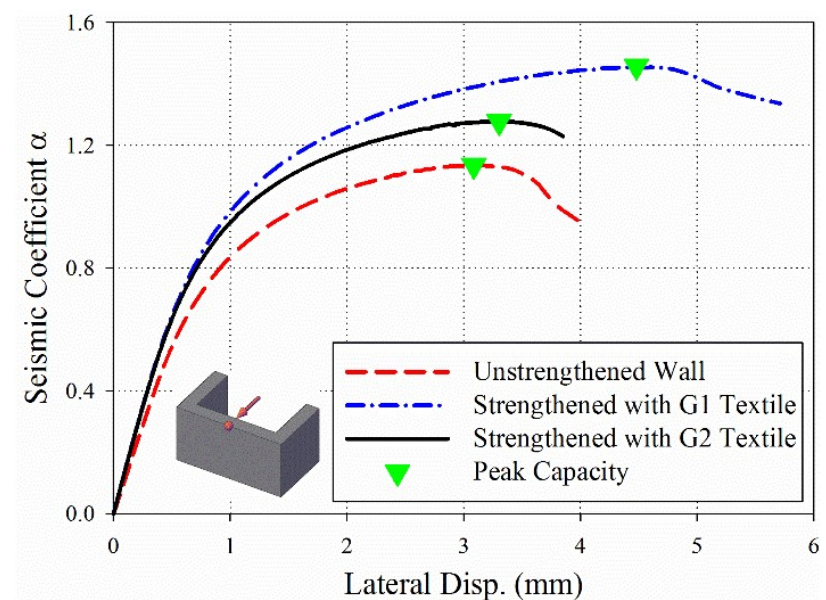

Fig.11. Pushover analysis of the strengthened solid models in the negative out-of-plane direction

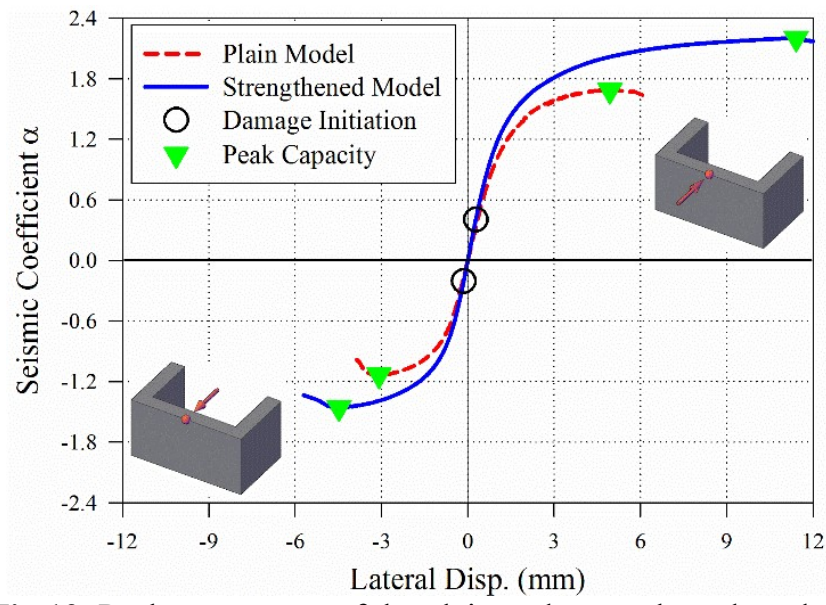

Fig.12. Pushover curves of the plain and strengthened models

The contours of lateral displacements of both plain and strengthened models pushed in the negative direction are presented in Fig.13. For the sake of brevity, only this critical direction is here discussed. By comparing the experienced lateral displacements of the strengthened model with those of the plain one at the peak capacity of the plain model (see Fig.13a and b), it is possible to distinguish a significant reduction especially in the midspan section (mid-span bending) of the web. This was expected due to previously mentioned increase in the lateral stiffness of the wall. On the other hand, the displacement contour of the strengthened model at its peak capacity exhibits considerable improvements with respect to the unstrengthened case. For instance, a larger section of the strengthened web tends to deform, meaning that a greater resistance against out-of-plane actions is achieved. Furthermore, a higher contribution of the wing walls is evident for the strengthened model. 


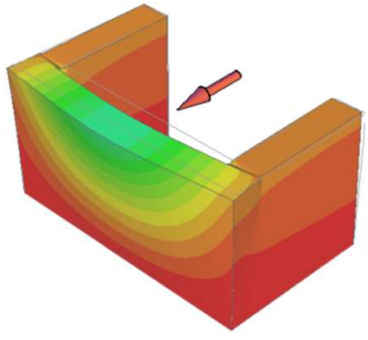

(a)

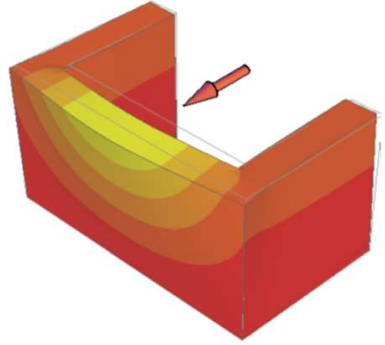

(b)

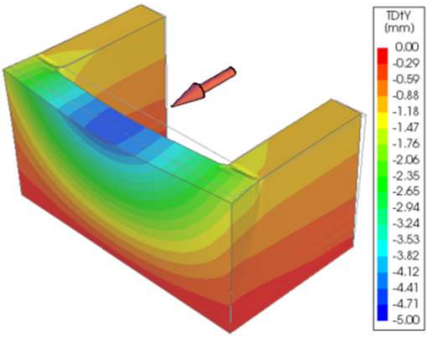

(c)

Fig.13. Total lateral displacements of the models pushed in the negative direction: (a) plain model at its peak capacity (b) strengthened model at the peak capacity of the plain model (c) strengthened model at its peak capacity

The contours of the principal tensile strains in the rammed earth for both plain and strengthened models are presented in Fig.14, which additionally presents the individual strain contours of the LC-TRM strengthening. A considerable reduction in the principal tensile strain levels was observed for the strengthened model at a lateral load equal to the peak capacity of the plain one (see Fig.14a and b). As it can be seen, the detachment of the web from the wing walls and the bending of the web's midsection are delayed. Furthermore, the tensile strains at the base of the wall are decreased. This situation can be interpreted as an improvement of the integrity and lateral stiffness of the wall due to the application of the strengthening. In other words, the employed strengthening solution enables the wall to redistribute the stresses and decreases its tendency to overturn. The contour of the principal tensile strains of the strengthened model at its peak capacity is presented in Fig. 14c, which shows that the final failure mechanism is similar to that of the plain model, while apparently a larger midsection of the web is bending. As previously stated, this larger section means that a higher lateral load is required to initiate the collapse mechanism. Moreover, the high strain values concentrated at the base demonstrates the efficiency of the applied strengthening in preserving the integrity of the model.

Regarding the damage in the strengthening composite material at the peak capacity of the strengthened model (see Fig.14d), it is clear that strengthening contributes to the stress transferring in regions of the rammed earth that are prone to fail, i.e. at the connections of the web with wing walls and also at the base. Thus, the efficiency of the TRM-strengthening in enhancing the out-of-plane response of the rammed earth components is numerically demonstrated. 


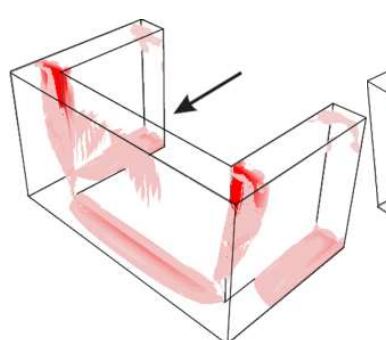

(a)

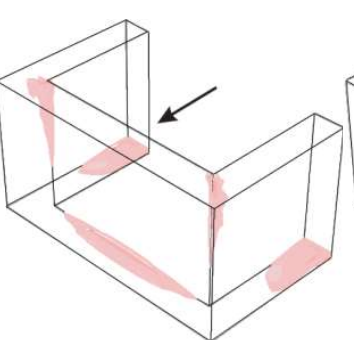

(b)

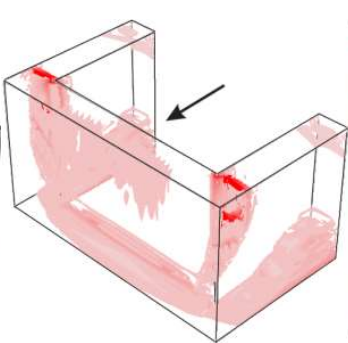

(c)

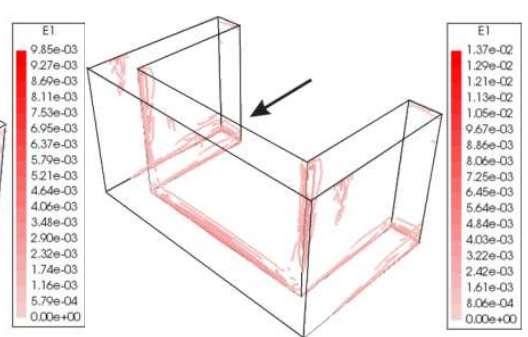

(d)

Fig.14. Principal tensile strains of the models pushed in the negative direction: (a) plain model at its peak capacity (b) strengthened model at the peak capacity of the plain model (c) strengthened model at its peak capacity (d) LC-TRM strengthening at peak capacity of the strengthened model

\subsection{Influence of damage on dynamic properties}

During the pushover analyses, the damage initiates and develops leading to a progressive reduction of the stiffness. In this regard, eigenvalue analyses were conducted at selected steps of the analyses of the models (plain and strengthened) pushed in the negative direction, starting with the initial undamaged condition up to the peak capacity. Hence, the changes in frequencies are considered as an indicator of damage state in the walls. The detailed analysis of the results confirmed the progressive reduction in frequencies of the models with damage progression and demonstrated that the damage also changes the mode shapes and modal mass contributions of the modes. Therefore and for the sake of simplicity, the three modes with the highest effective modal mass contribution in the undamaged condition were selected for comparison. Furthermore, the mode shapes of these selected modes were also considered in each evaluated step to find the modes more compatible with the original ones. As the orders of the modes are not necessarily identical in all considered steps, they are called hereafter as high participating modes (HM). The frequencies of each HM were normalized to the initial frequency value (corresponding to the undamaged state) as a function of the corresponding displacement at the control node, as represented in Fig.15. It can be observed that the greatest frequency reduction generally belongs to the mode with the highest contribution (HM2 in this case).

The changes in frequencies of the strengthened models are presented in Fig.15b, which also shows a reduction of the frequencies with damage development, though a smaller reduction can be interpreted as the efficiency of the strengthening in limiting damage. The maximum frequency drop in the plain model is of about $30 \%$, while the corresponding value for the strengthened model is about $22 \%$. It should be noted that these reduction values do not correspond to identical lateral displacement values. In other words, the strengthened model experienced less damage at higher lateral displacement values, which clears its efficiency in damage reduction. 
The analysis of the effective modal mass of the HMs can also clarify the damage pattern evolution of the models during the pushover analyses and its influence on the changes in stiffness. In this regard, the effective modal mass in each step is normalized to the corresponding value at the initial undamaged state. As it is clear from Fig.16, the applied strengthening does not considerably change the modal characteristics of the model, meaning that the development of the damage pattern is similar in both plain and strengthened models. Furthermore, the contribution of HM2 is shown to drastically decrease in both models in favor of the increase in contribution of HM1, while the effective model mass of HM3 shows minor variations. This behavior results from the influence of the progressive detachment of the web from the wing walls on the dynamic behavior of the models.

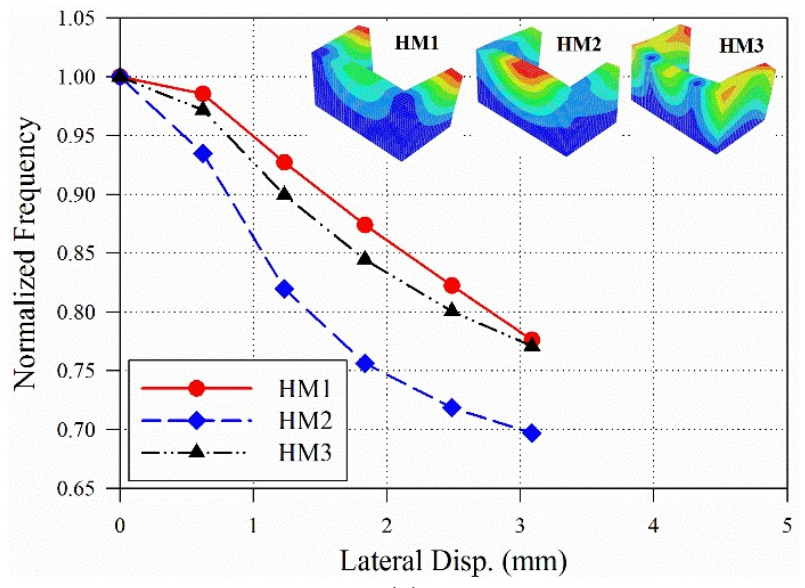

(a)

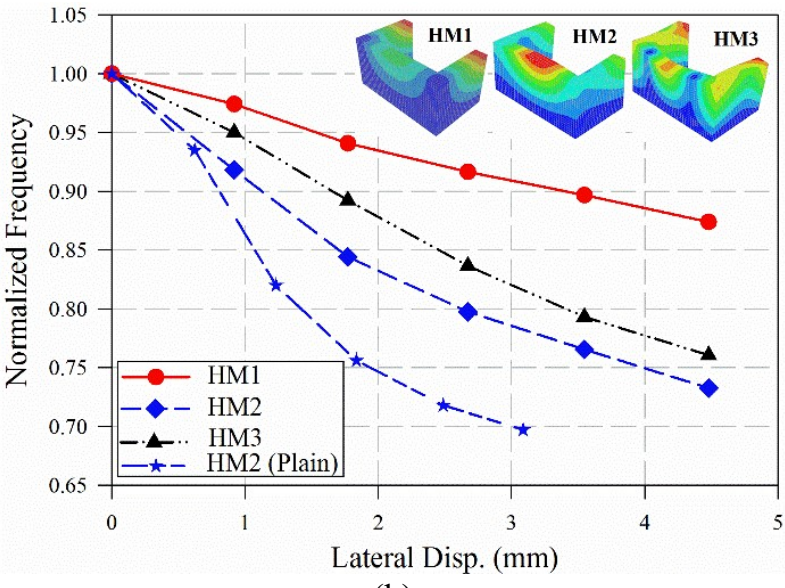

(b)

Fig.15. Reduction in frequencies of the models during the pushover analyses in the negative direction: (a) plain model (b) strengthened model

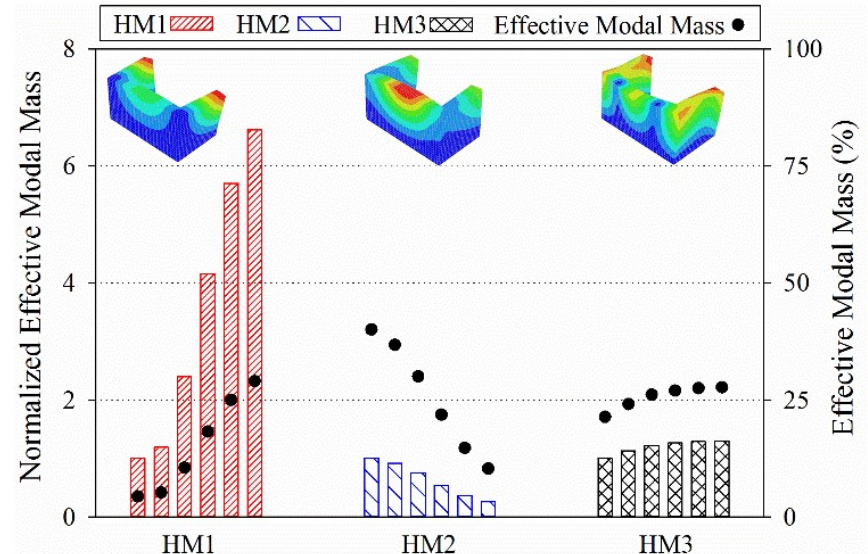

(a)

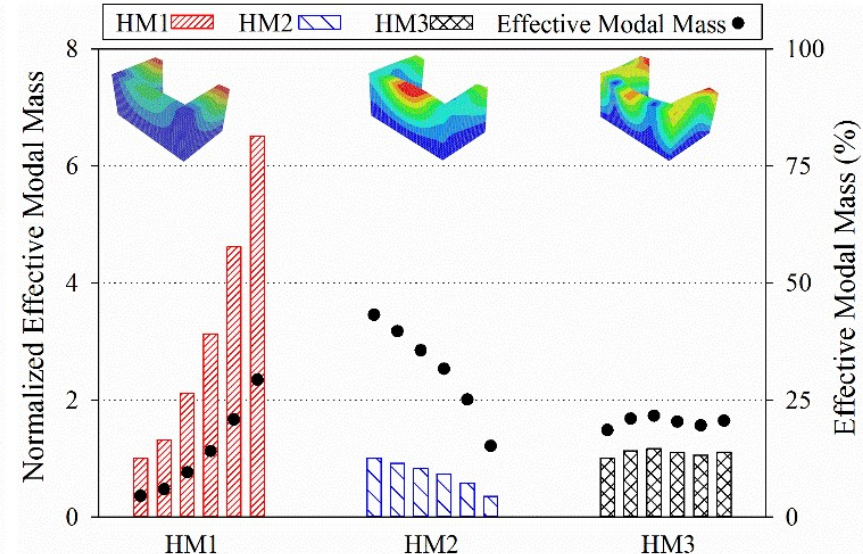

(b)

Fig.16. Changes in the effective modal masses of the models during the pushover analyses and pushed in the negative direction: (a) plain model (b) strengthened model 


\section{Dynamic Analyses}

In addition to the pushover analyses, incremental dynamic analyses (IDA) [36] were also performed to evaluate the seismic capacity of the plain and strengthened out-of-plane models. Furthermore, performing the IDA allowed evaluating the accuracy of the pushover analysis in predicting the seismic behavior of the models. This section starts by presenting the employed ground motion input and damping conditions. Then, the main outcomes of the IDA are discussed and compared with those from pushover analyses.

\subsection{Seismic input and time-history procedure}

The reliability of time-history analyses is a function of the proper ground motion input selection, which should be compatible with the seismicity characteristics of the hosting region. It can be selected from previously recorded seismic events or it can be generated artificially; though each approach has its own drawbacks. For instance, selecting ground motion records from previous events may not exactly satisfy the seismological conditions of the site, requiring scaling of the ground motion. In this regard, a variety of methods are proposed in the literature, nevertheless it should be highlighted that diversity in the outcome should be expected by following this procedure [37-38]. On the other hand, artificial ground motion records may not precisely represent the frequency and energy contents of a real earthquake. The discussion of these drawbacks is beyond the scope of the current article; though it should be noted that both approaches are valid options to proceed with the dynamic analyses. In this case, it was preferred to use an artificially generated ground motion.

The municipality of Odemira in Alentejo region, Portugal was selected as the site location of the rammed earth subassembly, being worthwhile to mention that this region presents and important rammed earth built heritage and moderate seismic hazard [39]. Fig.17a presents the corresponding design spectrum and the characteristics of the artificial ground motion record derived from the Portuguese national annex of Eurocode 8 [40] for the nearfield scenario. Moreover, Fig.17a also situates the modes with the highest modal mass participation of the plain model within the considered spectrum. As it can be seen, all modes are in the initial branch of the spectrum, which shows the sensitivity of the model to earthquakes with high-frequency content.

The Simqke-gr software [41], developed at the University of Brescia, was employed to generate an artificial ground motion record compatible with the considered elastic design spectrum. This process is controlled considering the acceleration and displacement design spectrums, for which an acceptable agreement should be 


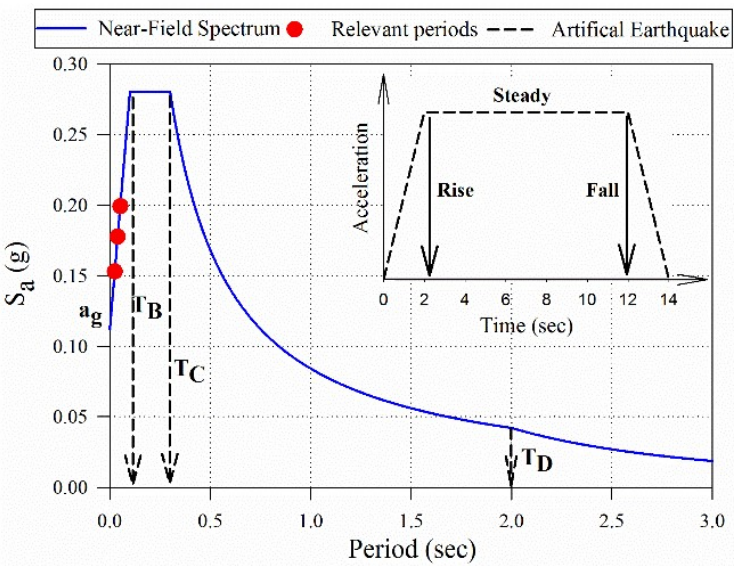

(a) applied at the base of the model in the y-direction.

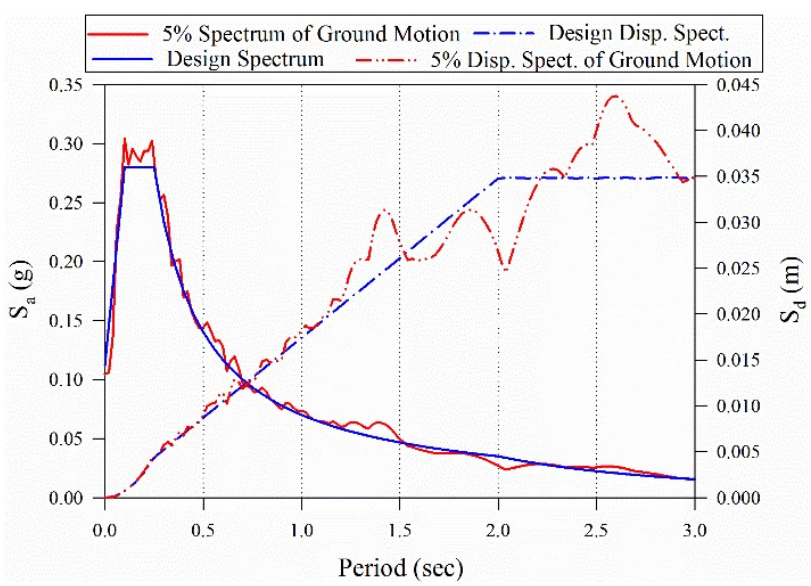

(b)

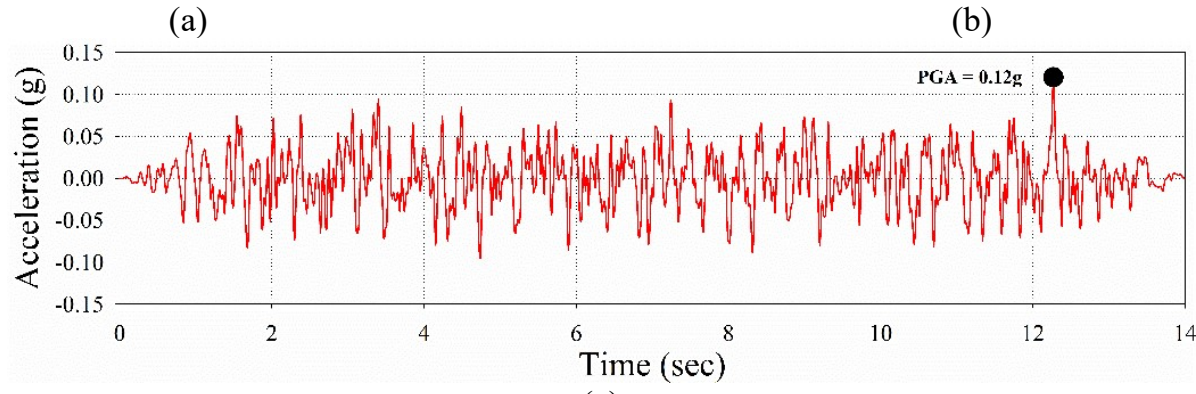

(c)

obtained (see Fig.17b). The SeismoSignal software [42] was then used to perform a baseline correction by filtering the frequencies below $0.1 \mathrm{~Hz}$ and above $20 \mathrm{~Hz}$. In conclusion, the accelerogram shown in Fig. 17c was

Fig.17. Artificially generated ground motion: (a) design spectrum for near field (type2) earthquakes in Odemira (southern Portugal) and corresponding artificial earthquake characteristics (b) acceleration and displacement response spectra of the generated ground motion record (c) earthquake input

Additionally, it is crucial to define a proper damping of the system to take into account the energy dissipation. In this regard, the Rayleigh damping approach is here adopted. This approach requires selecting the principal modes and assigning them a damping coefficient. These natural frequencies should be chosen in a way that the constructed damping matrix correctly characterizes the dissipative behavior of the rammed earth model in the desired frequency range. In this regard, the modes with significant mass participation were selected. Although, there is no general consensus about the damping ratio value in rammed earth constructions, in-situ dynamic identification tests [25] resulted in damping ratios of the studied rammed earth buildings in the range of 2.5$4.0 \%$. Hence, a $3 \%$ viscous damping ratio was considered in the current study. 


\subsection{Incremental dynamic analysis versus pushover analysis}

The plain and strengthened models were subjected to IDA by scaling up (step by step starting from 1.0 up to the failure of the subassembly [36]) the artificially generated ground motion record with the main purpose of extracting the corresponding envelope of the hysteretic behavior (see example in Fig.18a), which relates the seismic coefficient to the lateral displacement of the control node at top of the web wall's mid-section (same node considered in the pushover analyses). The extracted envelopes of the plain and strengthened models for identical scale factors are presented in Fig.18b, where they are compared with the respective pushover capacity curve. It is clear that the strengthened model experienced lateral displacements substantially lower than those of the plain one. Furthermore, the area of the hysteretic curves' envelope, related to the dissipated energy, evidences an important enhancement with respect to the energy dissipation capacity. Regarding the comparison with the pushover curves, it seems that they lead to misleading estimation of the load and displacement capacities, as it is later discussed.

The results of the IDA were further investigated using two approaches, namely based on the peak experienced displacements (displacement-based) and on the maximum induced base shear forces (force-based). The objective is to evaluate the reliability of the pushover analyses in predicting the load and displacement capacities of the rammed earth subassembly under study. The results are only presented for the critical out-of-plane direction in Fig.18c and d, respectively for the plain and strengthened models. As it can be observed, the pushover curves have a relatively good agreement with the force-based IDA curves, in both models, but they cannot accurately predict the ultimate displacement capacity. Regarding the pushover curve of the plain model, it falls outside the capacity range (limited by force- and displacement-based IDA curves), particularly at peak load. In turn, the pushover curve of the strengthened model falls within the corresponding capacity range. The differences observed between pushover and time-history behaviors, discussed above, can be due to a deficiency of the pushover analysis in predicting damage evolution, which leads the stiffness loss to be clearly different in the two analysis strategies. 


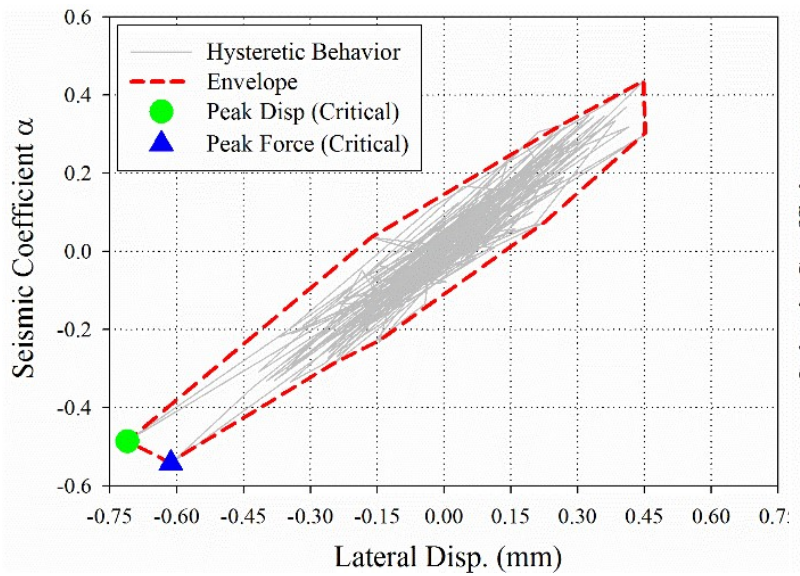

(a)

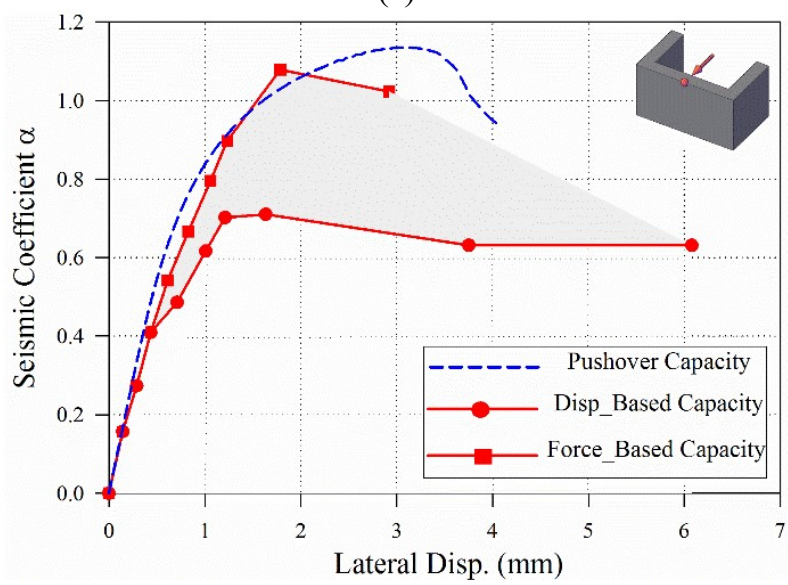

(c)

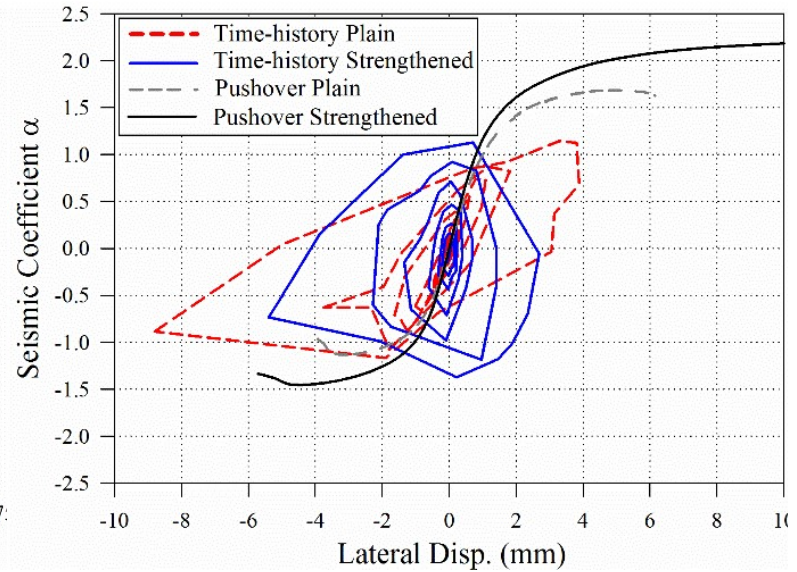

(b)

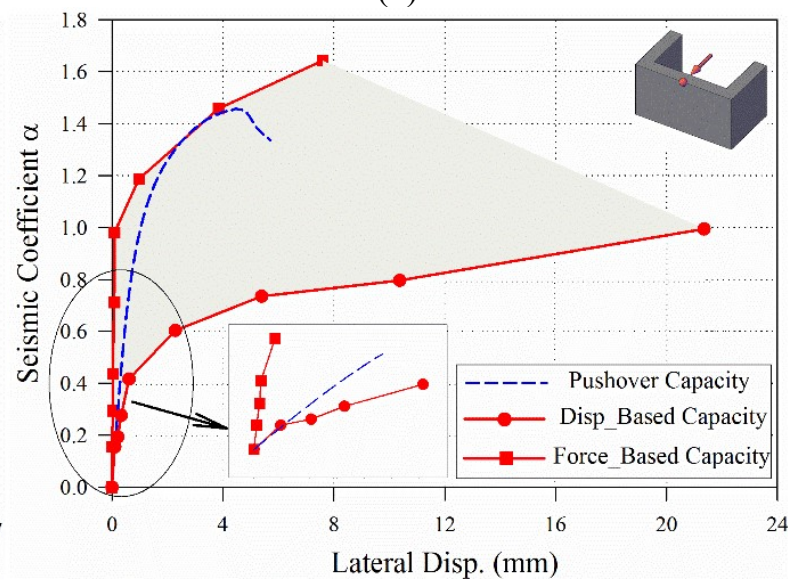

(d)

Fig.18. Results of the IDA: (a) example of the hysteretic behavior curve for the plain model (scale factor of 4.0) (b) hysteretic curves' envelopes of the plain and strengthened models (c) displacement- and force-based IDA curves of the plain model (d) displacement- and force-based IDA curves of the strengthened model

\section{Conclusions}

The primary objective of the current study was to assess the out-of-plane seismic behavior of a representative rammed earth subassembly and evaluate the mechanical efficiency of a low-cost TRM strengthening solution, which was achieved by conducting a series of advanced nonlinear static and dynamic analyses. Furthermore, the outcomes of this research serve to support the design of a near future shaking table test and to provide an insight into advanced approaches for predicting the seismic behavior of rammed earth structures. The outcomes of the mass-proportional pushover analyses showed that the critical direction of the plain model corresponds to pushing it outside the wing walls and that the out-of-plane failure mechanism consists on the detachment of the web wall from the wing (transversal) walls, bending of the mid-span section of the web and overturning of each wall of the component. Furthermore, damage (cracking) was found to initiate at very low lateral load levels due to the relevant nonlinear behavior of rammed earth. 
Regarding the modeling of the strengthening composite system, the clear lack of experimental evidence on the bond between substrate/mortar and mortar/mesh led to assume, at this stage, a perfect bond behavior. Despite the limitations inherent to this simplification in reproducing the behavior of the strengthening system, it allowed for a first and minimally reliable insight into the expected behavior of the strengthened subassembly. In this regard, the TRM strengthening was found to slightly increase the pre-peak lateral stiffness of the model subjected to pushover analyses, though it did not promote a delay on the damage initiation. The clear influence of the strengthening system was visible through the increase of about $45 \%$ and $29 \%$ in terms of displacement and load capacities in the critical direction, respectively.

Conducting modal analyses at different steps of the pushover curves allowed evaluating the damage development of the models. The main conclusion is that the strengthening led to a lower maximum drop of the higher contributing modes at failure of the models $30 \%$ and $20 \%$ for the plain and strengthened models, respectively), despite the strengthened one achieving higher lateral displacements. Thus, the strengthening solution is found to delay the global damage development in the rammed earth component.

Finally, the incremental dynamic analyses carried out allowed concluding about the reliability of the pushover approach in predicting the seismic behavior of rammed earth structures. In general, the pushover curves of the models pushed in the critical direction were found to present good agreement with the force-based IDA curves. On the other hand, the displacement-based IDA curves show that the rammed earth subassembly can achieve greater displacement levels than those predicted by the pushover analyses.

\section{Acknowledgments}

This work was financed by FEDER funds through the Competitively Factors Operational Programme COMPETE and by national funds through FCT - Foundation for Science and Technology within the scope of projects POCI-01-0145-FEDER-016737 (PTDC/ECM-EST/2777/2014) and POCI-01-0145-FEDER-007633. The support from grant SFRH/BPD/97082/2013 is also acknowledged.

\section{References}

[1] Houben H, Guillaud H. Earth Construction - a Comprehensive Guide. $3^{\text {rd }}$ Edition. London, UK: CRATerre EAG, Intermediate Technology Publication; 2008.

[2] Bui QB, Morel JC. Assessing the Anisotropy of Rammed Earth. Construction and Building Materials 2009; 23(9): 3005-3011. 
[3] Schroeder H. Sustainable Building with Earth. Springer; 2016.

[4] Parreira D J. Seismic Analysis of Rammed Earth Buildings. MSc Thesis, Portugal: Instituto Superior Técnico, Lisbon; 2007 [In Portuguese].

[5] Yamin LE, Philips CA, Reyes JC, Ruiz DM. Seismic Behavior and Rehabilitation Alternatives for Adobe and Rammed Earth Buildings. Proceedings of $13^{\text {th }}$ World Conference on Earthquake Engineering. Vancouver, Canada; 2004.

[6] Maniatidis V, Walker P. A Review of Rammed Earth Constructions for DTi Partners in Innovative Project "Developing Rammed Earth for UK Housing". University of Bath, Bath, UK, Natural Building Technology Group; 2003.

[7] Lilley DM, Robinson J. Ultimate Strength of Rammed Earth Walls with Openings. Proceedings of the Institution of Civil Engineers-Structures and Buildings 1995; 110(3): 278-287.

[8] Maniatidis V, Walker P, Heath A, Hayward S. Mechanical and Thermal Characteristics of Rammed Earth. Proceeding of international symposium on earthen structures. Bangalore, India; 2007.

[9] Miccoli L, Müller U, Fontana P. Mechanical Behavior of Earthen Materials: A Comparison Between Earth Block Masonry, Rammed Earth and Cob. Construction and Building Materials 2014; 61: 327-339.

[10] Wang Y, Wang M, Liu K, Pan W, Yang X. Shaking Table Tests on Seismic Retrofitting of Rammed Earth Structures. Bulletin of Earthquake Engineering 2016; 15(3): 1037-1055.

[11] Correia MR, Varum H, Lourenço PB. Common damages and recommendations for the seismic retrofitting of vernacular dwellings, Seismic Retrofitting: Learning from Vernacular Architecture. London, UK, Taylor \& Francis Group; 2015.

[12] Figueiredo A, Varum H, Costa A, Silveira D, Oliveira C. Seismic Retrofitting Solution of an Adobe Masonry Wall. Materials and Structures 2013; 46(1): 203-219.

[13] Silva RA. Repair of Earth Constructions by Means of Grout Injection. PhD Thesis, Portugal: University of Minho, Guimarães; 2013.

[14] Librici C. Modeling of the Seismic Performance of a Rammed Earth Building. Master Thesis, Portugal: University of Minho, Guimarães; 2016.

[15] De Felice G, Santis SD, Garmendia L, Ghiassi B, Larrinaga P, Lourenço PB, Oliveira DV, Paolacci F, Papanicolaou CG. Mortar-Based Systems for Externally Bonded Strengthening of Masonry. Materials and Structures 2014; 47(12): 2021-2037.

[16] Michels J, Widmann R, Czaderski C, Allahvirdizadeh R, Motavalli M. Glass Transition Evaluation of Commercially Available Epoxy Resins Used for Civil Engineering Applications. Composites Part B: Engineering 2015; 77: 484-493.

[17] Allahvirdizadeh R, Rashetnia R, Dousti A, Shekarchi M. Application of Polymer Concrete in Repair of Concrete Structures: A Literature Review. Proceedings of Concrete Solutions, $4^{\text {th }}$ International Conference on Concrete Repair. Dresden, Germany; 2011.

[18] Valluzzi MR, Modena C, De Felice G. Current Practice and Open Issues in Strengthening Historical buildings With Composites. Materials and Structures 2014; 47(12): 1971-1985.

[19] Mininno G. Modeling of the behavior of TRM-strengthened masonry walls. Master Thesis, Portugal: University of Minho, Guimaraes; 2016.

[20] Ascione L, De Felice G, De Santis S. A Qualification Method for Externally Bonded Fiber Reinforced Cementitious Matrix (FRCM) Strengthening Systems. Composites Part B: Engineering 2015; 78: 497-506.

[21] Mordanova A, Santis SD, De Felice G. State-of-the-art Review of Out-of-plane Strengthening of Masonry Walls with Mortar-Based Composites. Proceeding of $10^{\text {th }}$ International Conference on Structural Analysis of Historical Constructions: Anamnesis, Diagnosis, Therapy, Controls (SAHC). Leuven, Belgium; 2016.

[22] Garofano A, Ceroni F, Pecce M. Modeling of the In-plane Behavior of Masonry Walls Strengthened with Polymeric Grids Embedded in Cementitious Mortar Layers. Composites Part B: Engineering 2016; 85: 243258.

[23] Ciancio D, Augarde C. Capacity of Unreinforced Rammed Earth Walls Subjected to Lateral Wind Force: Elastic Analysis versus Ultimate Strength Analysis. Materials and Structures 2013; 46 (9): 1569-1585.

[24] Miccoli L, Oliveira DV, Silva RA, Müller U, Schueremans L. Static Behaviour of rammed earth: experimental testing and finite element modeling. Materials and Structures 2015; 48 (10): 3443-3456.

[25] Bui QB, Hans S, Morel JC, Do AP. First Exploratory Study on Dynamic Characteristics of Rammed Earth Buildings. Engineering Structures 2011; 33: 3690-3695.

[26] Mendes N, Costa AA, Lourenço PB, Bento R, Beyer K, De Felice G, Gams M, Griffith MC, Ingham JM, Lagomarsino S, Lemos JV, Liberatore D, Modena C, Oliveira DV, Penna A, Sorrentino L. Methods and Approaches for Blind Test Predictions of Outof- Plane Behavior of Masonry Walls: A Numerical Comparative Study. International Journal of Architectural Heritage 2017; 11(1): 59-71.

[27] Correia M. Rammed Earth in Alentejo. Lisbon: Argumentum; 2007. 
[28] Silva RA, Oliveira DV, Schueremans L, Lourenco PB, Miranda T. Modelling the Structural Behaviour of Rammed Earth Components. In: Topping BHV, Iványi P, editors. Proceedings of the $12^{\text {th }}$ International Conference on Computational Structures Technology. Scotland: Civil-Comp Press; 2014.

[29] DIANA FEA BV, 2017. DIsplacement method ANAlyser. Release 10.1, Netherlands.

[30] Silva RA, Oliveira DV, Schueremans L, Miranda T, Machado J. Effectiveness of the Repair of Unstabilised Rammed Earth with Injection of Mud Grouts. Construction and Building Materials 2016; 127: 861-871.

[31] Barroso CA. Innovative Seismic Strengthening of Rammed Earth Constructions. MSc Thesis, Portugal: University of Minho, Guimarães; 2017 [in Portuguese].

[32] Oliveira DV, Silva RA, Barroso C, Lourenco PB. Characterization of a Compatible Low Cost Strengthening Solution Based on the TRM Technique for Rammed Earth. Key Engineering Materials 2017; 747: $150-157$.

[33] Allahvirdizadeh R. Modelling of the Seismic Behaviour of TRM-Strengthened Rammed Earth Walls. MSc Thesis, Portugal: University of Minho, Guimarães; 2017.

[34] Allahvirdizadeh R, Gholipour Y. Reliability Evaluation of Predicted Structural Performances Using Nonlinear Static Analysis. Bulletin of Earthquake Engineering 2017; 15(5): 2129-2148.

[35] Allahvirdizadeh R, Khanmohammadi M, Marefat MS. Probabilistic Comparative Investigation on Introduced Performance-Based Seismic Design and Assessment Criteria. Engineering Structures 2017; 151: 206-220.

[36] Vamvatsikos D, Cornell CA. Incremental Dynamic Analysis. Earthquake Engineering and Structural Dynamics 2001; 31(3): 491-514.

[37] Watson-Lamprey JA. Selection and Scaling of Ground Motion Time-Series. PhD Thesis, USA: University of California, Berkeley; 2007.

[38] Allahvirdizadeh R, Khanmohammadi M, Marefat MS Investigating Effects of Scaling and Selecting Earthquake Ground Motions on Performance-Based Design of RC Buildings. Proceedings of the $4^{\text {th }}$ International Conference on Concrete \& Development. Tehran, Iran; 2013.

[39] Silva RA, Mendes N, Oliveira DV, Romanazzi A, Dominguez-Martinez O, Miranda T. Evaluating the Seismic Behaviour of Rammed Earth Buildings from Portugal: from Simple Tools to Advanced Approaches. Engineering Structures 2018; 157: 144-156.

[40] IPQ. NP ENV 1998-1: Eurocode 8: Design of Structures for Earthquake Resistance - Part 1: General rules, seismic actions and rules for buildings. Lisbon: Instituto Português da Qualidade; 2009.

[41] Simqke_gr, 2012. Program for Generating Spectrum-Compatible Artificial Accelerograms. Available at URL: http://gelfi.unibs.it/software/simqke/simqke gr.htm.

[42] Seismosoft, 2016. SeismoSignal - A Computer Program for Signal Processing of Time-Histories. Available at URL: www.seismosoft.com. 